Review

\title{
Electrogastroenterography in clinical practice
}

\author{
Pavel M. Kosenko ${ }^{1}$, Sergey A. Vavrinchuk ${ }^{2}$ \\ ${ }^{1}$ Far East State Medical University, Khabarovsk, Russia \\ ${ }^{2}$ Health care specialists performance improvement institute, Khabarovsk, Russia
}

Received 21 February 2013, Revised 21 March 2013, Accepted 15 April 2013

C 2013, Kosenko P.M., Vavrinchuk S.A.

(C) 2013, Russian Open Medical Journal

\begin{abstract}
The review contains the information on the basics of electrophysiological evaluation of motor-evacuator function of stomach. It describes the main methods for registration of electric activity of stomach and intestine, characterizes the registered parameters, and gives modern data on its clinical application.
\end{abstract}

Keywords: electrophysiology, peripheral electrogastroenterography, motor evacuator function, stomach, intestine

Cite as Kosenko PM, Vavrinchuk SA. Electrogastroenterography in clinical practice. Russian Open Medical Journal $2013 ; 2: 0203$.

Correspondence to Kosenko Pavel. Address: 67/64, Sheronova str., Khabarovsk, 680030, Russian Federation. Phone: +79625025206.

E-mail: kosenko@inbox.ru

One of the most important properties of smooth muscle tissue of gastrointestinal tract (GIT) is its ability to spontaneously generate and conduct electric potentials by pacemaker areas [1-5]. Its work causes the appearance of regular, rhythmic fluctuation of stomach and intestine called slow waves (SW) or basal electric rhythm (BER) [6-9].

Pacemaker areas are detected at the border with cardia section of the stomach and its pre-pyloric part [1, 10-12], at the duodenum on the level of influx of bile and pancreatic ducts, and in the ileum [13]. It is thought that the pacers are the interstitial Kachal cells $[14,15]$.

Basis electric activity (EA) that is constantly present is accompanied by periodically appearing activity potentials called spike activity [11].

There are basis (second), minute, hourly electric rhythms and food consumption rhythms called SW-activity $[2,11,13,16,17]$.

BER frequency is 1 to 22 fluctuations per minute $[1,18]$.

Specificity of BER frequencies for each GIT section described by W.C. Alvarez [4, 19], was the base for introduction of electrophysical methods of EA study of different GIT sections.

In 1981 V.G. Rebrov developed the classification of GIT bioelectric waves [9]. Frequency range of the stomach is 2 to 4 cycles per minute $[5,12,20]$.

Consumption of food, several pharmaceuticals, as well as pathologic processes of the abdominal cavity cause the disappearance of migrating minute complex, instead of which persistent EA amplification appears up to the end of stimulating factor [21].

Electrophysiological appearances of periodic activity of GIT are the change of range and frequency parameters of SW activity and spike activity intensity $[5,10,11,20-22]$.
During the last 50 years there was proven close relation between EA and motor activity of GIT. It was established that BER defines maximal possible frequency of smooth muscles contraction of stomach and intestine, and its frequency matches the frequency of contraction of smooth muscles of studied section of GIT $[11,13,23-26]$.

BER is the base for coordination of the work of different GIT sections; however the appearance of contractions and their intensity are related to spike activity parameters [13].

EA is defining relative to the appearance of smooth muscle contractions of stomach and intestine with appearance of contractions depending not only on stimuli present but on readiness of the muscle itself to answer to it with contraction $[6,8$, $9,11,20,23,27]$.

In order to evaluate EA of GIT organs both invasive and noninvasive study methods are used. The first include electromyography (EMG), the second - cutaneous electrogastrography (EGG) and electrogastroenterography (EGEG) [5].

EMG of GIT organs is performed using electrodes implanted in their mucosa or using suction electrodes on special catheters entered in the stomach, large intestine or small intestine $[5,10$, $11,27,28]$.

The disadvantages of EMG include invasiveness and difficulty, registration of only local EA in the places of electrodes implantation [10].

In 1922 W.C. Alvares proposed the EGG method which is the registration of the change of total electric potential of the stomach from the human body surface by installing active electrode above stomach in the view of its antral section [4]. 
First fundamental studies of EGG in our country were performed by M.A. Sobakin [11], after which the active use of EGG in experimental and clinical studies began [17, 18, 29-40].

Thus, M.I. Kuzin et al. (1985) consider EGG one of the primary methods for evaluation of ulcer stenosis severity [41].

O.L. Notova (1987) and N.S. Tropskaya (1994) proved the possibility of the detection of hourly rhythms of gastric and intestinal EA using EGEG method including the registration of the changes in total electric potential of stomach and intestine from the human body surface $[13,23]$. The beginning of use of the method was related to the multichannel electrogastrograph development [27].

The validity of the method of cutaneous registration of GIT biopotentials was proven on the stomach frequencies using parallel X-ray, edoscopic study and EMG [5, 11-13, 43, 44].

In Russian Federation EGEG is usually called peripheral EGEG (PEGEG) [23, 37].

The advantages of PEGEG over EMG include non-invasivity, possibility of long-term and multiple use, and also of simultaneous evaluation of integral EA of different stomach sections. The method is of higher information value than EGG since it also provides for evaluation of EA of different intestinal sections $[1,17$, 23, 29, 30, 38, 39].

All the quantity parameters of EA GIT are divided into amplitude and frequency, as well as absolute and relative [1,37].

Amplitude parameters include amplitude (A) of the fluctuations of bioelectric potential on BER frequencies of reviewed GIT part and the power $(\mathrm{P})$ spectrum. Usually there are calculated total power (Ps) and power on the BER frequencies for different GIT sections (Pi) [1, 17, 37].

The frequency parameters involved dominating and average frequency of PEGEG in the BER range of the GIT section [18].

Relative amplitude parameters are the ratio of the parameter calculated for one or several GIT sections to the similar parameter for other(-s) GIT sections, as well as ratio of the values for the same parameter calculated in the different time moments and their derivatives $[17,18]$.

D.B. Zakirov (1994) in order to evaluate the rhythmic of different GIT sections introduced the rhythmic coefficient which is the ratio of the length of spectrum envelope to the length of the spectrum section of study section and also characterizes the rhythmic of the contractile activity and the propulsive peristalsis [17].

In order to evaluate the rhythmic of GIT EA the "instability of dominating frequency" is determined, as well as the respective spectrum power - "index of power instability" [23].

The most used frequency parameter is the percent content of the parameters in the frequency ranges $2-4 \mathrm{~Hz}, 0-2 \mathrm{~Hz}$ and $4-10 \mathrm{~Hz}$, called normo-, tachy- and bradygastrias [9, 21, 23, 37].

Coordination of GIT operation shall be evaluated as the range of the amplitude or power of PEGEG on the frequencies of superior section to the similar parameter of the inferior section called "ratio coefficient" (Pi/Pi+1) [30, 32, 37-40].

S. Yochitomi et al. (1996) considered the work of stomach and intestine coordinated when the amplification of PEGEG range after food load in the stomach range was accompanied by the amplification of EA in the intestine range with short delay [42]. Y. Koike et al. (1995) introduced the term of coordination index defined by them as the ratio of the coefficient of increase of EA amplitude of small intestine to the coefficient of increase of EA amplitude of the stomach after food load [46].

To evaluate the degree of compensation of stomach motorics in the patients with ulcerative pyloroduodenal stenosis and the diagnostics of its post-operational disorders there were proposed the compensation parameters for electric and peristalsis activity of stomach [30].

Food stimulation is a common recognized criteria for evaluation of GIT functional state, causing in the pathological conditions the change of frequency parameters depending on its type $[3,4,23]$.

The most widespread area of PEGEG use is the surgical pathology of the intestinal organs. The purpose of PEGEG use in the post-operational period is the evaluation of severity of GIT motor function disorder justified by post-operational paresis of stomach and intestine, prediction of possible complications and evaluation of effectiveness of the treatment performed $[1,17,18$, $30,32,34,40]$.

PEGEG is most frequently used for ileus of different etiology [4, 11].

L.K. Kulikov, A.A. Smirnov, I.M. Jajanidze, after studying the electric activity of gastrointestinal tract in the patients with acute destructive pancreatitis established the connection between disorders of motor-evacuator function of gastrointestinal tract and purulent complications of pancreonecrosis [32].

A.A. Smirnov proposed to use the coefficient of severity degree of gastrointestinal tract paresis in the patients with peritonitis in order to make the objective diagnostics of paralytic intestinal obstruction [40].

There are the data on its use at gallstone disease $[33,45]$ and mesenteries thrombosis [37].

Lately PEGEG is gaining the increasing popularity in therapeutic gastroenterology with the objects of interest of the investigators being not only the separate nosologies but also functional disorders such as functional dyspepsia [47, 48], duodenal hypertension [36] and gastroesophageal reflux disease [31].

PEGEG is also used for evaluation of the effect of different pharmacologic drugs on the parameters of EA of stomach and intestine $[18,21,36]$.

Information on electrophysiological evaluation of violations of gastric motor-evacuation function at the ulcer disease using PEGEG are not plentiful and reflect only the most general principles of diagnostics of pyloroduodenal stenoses and postoperational gastrostases $[1,17,30]$.

Prospective direction for use of PEGEG is the use of multidimension statistic analysis with creation of mathematic models of gastrointestinal tract motorics disorder [30].

Based on the cluster and discriminate statistic analysis of PEGEG parameters there were detected hyper-and hypomotor types of gastric motorics disorder in patients with subcompensated pyloroduodenal stenosis [30].

Electrophysiological methods for evaluation of motor evacuator GIT function are being introduced to the modern clinical practice with the increasing frequency and are the prospective direction that allows detecting its disorders and perfecting the treatment methods. 


\section{Reference}

1. Biryaltsev VN, Berdnikov AF, Filippov VA, Veliev NA. Electrogastroenteriography in surgical gastroenterology. Kazan, Russia, 2003.

2. Lebedev NN. Biorhythms of digestive system. Medicine Publ., Moscow, Russia, 1987.

3. Repina LB, Blokhin BM, Troitskaya NB, Steshin VY. Electrogastrography of the stomach motility: from the days of origination to nowadays. Doctor.ru - Scientific and practical medical journal 2010; (52): 59. [Article in Russian]

4. Alwarez WC. The electrogastrogram and what it shows. JAMA 1922; 78(15): 1116-1119. (doi: 10.1001/jama.1922.02640680020008)

5. Koch KL, Stern RM. Handbook of Electrogastrography. Oxford University, New York, USA, 2004.

6. Chang FY. Electrogastrography: basic knowledge, recording, processing and its clinical applications. J Gastroenterol Hepatol 2005; 20(4): 502516. (doi: 10.1111/j.1400-1746.2005.03751.x) (PMID: 15836697)

7. Matsuura $Y$, Yamamoto $T$, Takada M, Shiozawa T, Takada H. Application of electrogastrography to public health. Nihon Eiseigaku Zasshi 2011; 66(1): 54-63. (PMID: 21358135)

8. Yin J, Chen JD., Electrogastrography: methodology, validation and applications. J Neurogastroenterol Motil 2013; 19(1): 5-17. (PMID: 23350042)

9. Rebrov VG. Registration of stomach and intestine potentials in clinical conditions. Ter archive 1981; (9): 24-30. [Article in Russian]

10. Onopriev VV. Pathogenesis of motor-evacuator disorders and compensation mechanisms during surgical correction of duodenum stenosis (experimental clinical study): MD thesis. Moscow, Russia, 2004. [Text in Russian]

11. Sobakin MA. Motor activity of stomach during digestion: MD thesis. Moscow, Russia, 1958. [Text in Russian]

12. Couturier D, Roze C, Paollagi J, Debray C. Electrical activity of the normal human stomach: A comparative study of recording obtained from the serosal and mucosal sides. Am J Dig Dis 1972;17: 969-976. (doi: 10.1007/BF02239136)

13. Tropskaya NS. Informative parameters in evaluation of organization of motor activity of gastrointestinal tract: PhD thesis. Moscow, Russia, 1994. [Text in Russian]

14. Takaki M. Gut pacemaker cells: the interstitial cells of Cajal (ICC). J Smooth Muscle Res 2003; 39(5): 137-61. (PMID: 14695026)

15. Rhee PL, Lee JY, Son HJ, Kim JJ, Rhee JC, Kim S, et al. Analysis of pacemaker activity in the human stomach. $J$ Physiol 2011; 589(Pt 24): 6105-6118. (PMID: 22005683) (doi: 10.1113/jphysiol.2011.217497)

16. Parkman HP, Hasler WL, Barnett JL, Eaker EY. Electrogastrography: a document prepared by the gastric section of the American Motility Society Clinical GI Motility Testing Task Force. Neurogastroenterol Motil 2003; 15(2): 89-102. (doi: 10.1046/j.1365-2982.2003.00396.x) (PMID: 12680908)

17. Zakirov DB. Evaluation of motor evacuator function of gastrointestinal organs in surgical patient: PhD thesis. Moscow, Russia, 1994. [Text in Russian]

18. Li LG. Informative parameters of peripheral electrogastroenterogram in the evaluation of functional state of stomach and small intestine: PhD thesis. Moscow, Russia, 2009.

19. Alvarez WC. Functional variations in contractions of different parts of the small intestine. Amer J Physiol 1914; 35: 177-193.

20. Chang FY. Electrogastrography: basic knowledge, recording, processing and its clinical applications. J Gastroenterol Hepatol 2005; 20(4): 502516. (doi: 10.1111/j.1400-1746.2005.03751.x)

21. Rebrov VG. Practical possibilities of electrogastrography with different leads. In: Modern issues of electrogastrography. Moscow, Russia, 1975: 173-176. [Text in Russian]

22. O'Grady G, Angeli TR, Du P, Lahr C, Lammers WJ, Windsor JA, et al. Abnormal initiation and con-duction of slow-wave activity in gastroparesis, defined by high-reso-lution electrical mapping. Gastroenterology 2012; 143: 589-598, e1-e3. (PMID: 22643349) (doi: 10.1053/j.gastro.2012.05.036)

23. Notova OL. Evaluation of the motor activity of stomach and different sections of intestine on the basis of the data of peripheral polyelectrography: PhD thesis. Moscow, Russia, 1987. [Text in Russian]

24. Chen JDZ, McCallum RW. Clinical applications of electrogastrography. American journal of Castroenterology 1993; 88(9): 1324-1336. (PMID: 8362825)

25. Koenig JB, Martin CE, Dobson H, Mintchev MP. Use of multichanne electrogastrography for noninvasive assessment of gastric myoelectrical activity in dogs. Am J Vet Res 2009; 70(1): 11-55. (PMID: 19119943) (doi: 10.2460/ajvr.70.1.11)

26. Wingate DL. Backwards and forwards with the migrating complex. Dig Dis Sci 1981;26(7): 641-667. (doi: 10.1007/BF01367678)

27. Lebedev NN, Trusov AN, Popova YuP. Broadband multichanne electrogastrography and periodical motorics of gastrointestinal tract. Fiziologiya cheloveka 1991; 17(4): 54-66. [Article in Russian]

28. Wang ZS, Elsenbruch S, Orr WC, Chen JD. Detection of gastric slow wave uncoupling from multi-channel electrogastrogram: validations and applications. Neurogastroenterol Motil 2003; 15: 457-465. (PMID: 14507347) (doi: 10.1046/j.1365-2982.2003.00430.x)

29. Burduli NM, Gutnova SK. Peripheral computer electrogastroentherography in the diagnostics of motor disorders in chronic pancreatitis. Russian Journal of gastroenterology, hepatology, coloproctology 2010; 20(5): 59. [Article in Russian]

30. Vavrinchuk SA, Kosenko PM. Systemic analysis of the parameters of peripheral electrogastroenterography in the patients with complicated ulcerative disorder. IPKSZ Publishing center, Khabarovsk, Russia, 2012. [Text in Russian]

31. Golub IV, Pasechnikov DV, Udovichenko TG, et al. Disorder of myoelectric gastric activity in patients with GERB. Russian Journal of gastroenterology, hepatology, coloproctology 2010; 20(5, Suppl. 36): 8. [Article in Russian]

32. Kulikov LK, Smirnov AA, Dzhadzhanidze IM, Cybikov SG, Buslaev AO, Privalov YuA. Functional disorders of gastrointestinal tract in patients after acute pancreatitis. Siberian Medicine Journal 2009; 86(3): 43-46. [Article in Russian]

33. Magomedov MS. Diagostics and treatment of disrupted digestion syndrome in gallstone disease: PhD thesis. Moscow, Russia, 2008. [Text in Russian]

34. Mikhalsky VV. Issues of management of early post-operational period in the patients operated with acute intestinal obstruction syndrome: PhD thesis. Moscow, Russia, 1997. [Text in Russian]

35. Nugaeva NR. Characteristics of electrogastrographical parameters in most prevalent stomach diseases and duodenal ulcer: PhD thesis. Moscow, Russia, 1999. [Text in Russian]

36. Ponomareva AP. Value of determiation of bioelectrical activity of gastrointestinal tract for diagnostics and choise of drug therapy for motor-evacuator function disorders in children: PhD thesis. Moscow, Russia, 2006. [text in Russian]

37. Smirnova GO. Peripheral electrogastroenterography in clinical practice. V.A. Stupin eds. Medpractica-M Publ., Moscow, Russia, 2009. [Text in Russian]

38. Smirnova GO, Siluyanov SV, Stupin VA. Peripheral electrogastroenterography in diagnostics of disorders of motor and evacuation function of gastrointestinal tract. Gastroenterology of Saint Petersburg 2010; (2-3): M84. [Text in Russian]

39. Smirnova GO, Siluyanov SV, Kornienko VN, Ardabatsky LA. New possibilities of electrogastroenterography for long-term monitoring of gastrointestinal drug motorics. Abstract book of XV Russian Gastroenterology Week, October 12-14. Russian Journal of gastroenterology, hepatology, coloproctology 2009; (5): 170. [Text in Russian] 
40. Smirnov AA. Diagnostics evaluation of electric activity changes of small intestine in patients with extensive peritonitis. PhD thesis. Irkutsk, Russia, 2006. [Text in Russian]

41. Kuzin MI, Pomelov VS, Alekseev AA, Bulgakov GA, Sal'man MM. Selective proximal vagotomy in the surgical treatment of ulcerative stenosis. Khirurgiia (Mosk) 1985; (2): 3-10. (PMID: 3981929) [Article in Russian]

42. Rebrov VG, Stankovsky BA, Kulanina GI. Particularities of registration of electric activity of stomach and intestine from the patient's body surface. Russian Journal of gastroenterology, hepatology, coloproctology 1996; (2): 48-52. [Article in Russian]

43. Hamilton JW, Bellahsene BE, Reichelderfer M, Webster JG, Bass P. Human electrogastrograms. Comparison of surface and mucosal recordings. Dig Dis Sci 1986; 31(1): 33-39. (PMID: 2934238)

44. Izbéki F, Wittmann T, Odor S, Botos B, Altorjay A. Synchronous electrogastrographic and manometric study of the stomach as an esophageal substitute. World J Gastroenterol 2005; 11(8): 1172-1178. (PMID: 15754399)

45. Yoshitomi S, Martin A, Murat J, Yamamoto M, Tanaka T, Ohshio G, Manabe T, Imamura M. Electrogastroenterographic Examination of 22 Patients Before and After Cholecystectomy. Digestive Diseases and Sciences 1996; 41(9): 1700-1705. (PMID: 8794782)

46. Kaneoke $Y$, Koike $Y$, Sakurai N, Washimi Y, Hirayama M, Hoshiyama M, Takahashi A. Gastrointestinal dysfunction in Parkinson's disease detected by Electrogastroenterography. J Auton Nerv Syst 1995; 50(3): 275-281. (PMID: 7714322)

47. Rachkova NS. Functional dyspepsia in adolescents. Principles of differentiated treatment: PhD thesis. Moscow, Russia, 2007. [Text in Russian]

48. Foryś S, Rudnicki C, Walecka-Kapica E, Chojnacki J. Electrogastrography in various clinical forms of functional dyspepsia. Pol Merkur Lekarski 2009; 26(155): 373-7. (PMID: 19606677)

Authors:

Pavel M. Kosenko - MD, PhD, Assistant, Department of general surgery, Far East State State Medical University, Khabarovsk, Russia;

Sergey A. Vavrinchuk - MD, D.Sc. Professor, Department of surgery, Health care specialists performance improvement institute, Khabarovsk, Russia. 